\title{
Identification and Assessment of Fluroquinolone Multidrug Efflux Pump in Multidrug Resistant Staphylococcus aureus isolated from Hospital Wastewater in Kuala Lumpur
}

\author{
Siti Norayuni Mohd Zulkeflle ${ }^{1}$, NurFarahaida Mustafa ${ }^{1}$, Nor'azizi Othman ${ }^{2}$, \\ Hirofumi Hara ${ }^{1, *}$
}

${ }^{1}$ Department of Environmental Engineering and Green Technology,

Malaysia-Japan International Institute of Technology, Universiti Teknologi Malaysia, Kuala Lumpur, 54100, MALAYSIA ${ }^{2}$ Department of Mechanical Precision Engineering,
Malaysia-Japan International Institute of Technology, Universiti Teknologi Malaysia, Kuala Lumpur, 54100,
MALAYSIA

*Corresponding Author

DOI: https://doi.org/10.30880/ijie.2019.11.07.002

Received 30 May 2019; Accepted 30 July 2019; Available online 10 August 2019

\begin{abstract}
Apart from alterations of target proteins of fluroquinolones, multidrug resistant (MDR) S. aureus can also mediated their resistance via overexpression of efflux pump. However, this mechanism is not well characterized. Absence of known antibiotic resistance genes (ARGs) in the MDR S. aureus isolates have led us to find other mechanism of resistance which could be responsible for their resistance. Therefore, this study was performed to identify the MDR efflux pump genes and evaluate the activity through Ethidium Bromide Cartwheel (EtBrCW) method. The MDR S. aureus were isolated from local hospital wastewater in Kuala Lumpur. 9 of the MDR S. aureus isolates were subjected to PCR for the detection of MDR efflux pump genes. The EtBrCW was used to demonstrate efflux activity as a mechanism of resistance in S. aureus. The result showed only 2 isolates possessed efflux pump genes with low efflux activity. It was observed that many of the isolates did not have conserved MDR efflux pump genes, suggesting there may be other mechanisms of resistance that need further exploration. The fast spreading of these resistance genes could pose serious risk to public health and emergence of superbug which is difficult to treat with available antibiotic.
\end{abstract}

Keywords: Multidrug resistant, Staphylococcus aureus, hospital wastewater, antibiotic resistant genes, efflux pump, efflux pump genes.

\section{Introduction}

Multidrug resistance (MDR) Staphylococcus aureus (S. aureus) remains as one of the most important bacterial pathogens in the public health domain due to its high virulence and capability to cause multiple ailments ranging from complicated skin infections to life threatening conditions such as pneumonia, endocarditis and toxic shock syndrome. This pathogen is relatively abundant both in the community and healthcare facilities. Besides its pathogenic potential, these bacteria have been able to develop resistance to almost all classes of antibiotics [1]. Excessive and overuse of these antibiotics in medical field resulting in many antibiotics are released in water environment coming from hospitals which increase the development of ARGs in bacteria [2]. Hospital effluent contained high numbers of antimicrobial residues and pathogens that are non-stop released into the environment especially in wastewater [3]. Moreover, hospital effluent is found to be main hotspots for horizontal genes transfer, which can spread the gene of ARGs and virulence 
factors whether among interspecies and intraspecies of the bacteria [4]. Horizontal gene transfer is the common mechanism to transfer the genetic information [5]. This method is common among bacteria because it is efficient to contribute to the development, maintenance, and spreading ARGs among the bacteria. Spread of these ARGs are becoming a great concern nowadays, because it could pose serious public health threats when disseminated to the natural environment such as river water. Additionally, certain pathogenic bacteria have been found in Malaysia's river water and this can be passed simply through drinking water and unexpectedly affected humans $[6,7]$. River water that is exposed to the risk of contamination should be studied carefully to avoid threaten human health and environmental quality [7]. Transfer of these resistance determinant to the river water could provide toxic effect on the microbial communities in the natural environment and development of superbug from the environment making the treatment of bacterial infections more difficult.

In Malaysia, the usage antibiotics has been increasing rapidly over the last decades till now. The classes of antibiotics that are most frequently prescribed by Malaysian hospitals are Penicillin, Cephalosporins, Fluroquinolones, Aminoglycosides, Sulfamethoxazole, Tetracycline and Phenicol. Starting in the 1950s, S. aureus developed resistance to penicillin. This is followed by resistance to methicillin, about a decade later, due to the activity of PBP2a protein [8]. Because of this, fluroquinolones and glyco-peptides class of antibiotics has remained as a common and effective therapy against $S$. aureus. Fluroquinolones antibiotic have been used for the treatment of severe or resistant $S$. aureus infections since the late of 1980s [9]. Fluoroquinolones are potent, broad-spectrum antibiotics that are derived from the quinolone family of antibiotics. It is synthetically constructed through modification of 1-alkyl-1,8-naphthyridin-4-one3 -carboxylic acid [10]. The use of fluoroquinolones for the effective treatment has been impaired by the rapid emergence of fluoroquinolone resistance. Fluoroquinolones resistance in S. aureus is mainly due to mutations in the quinolone resistance determining region (QRDR) of genes encoding the target enzymes (topoisomerase IV and DNA gyrase). Mechanisms of fluoroquinolone resistance in S. aureus have been extensively studied and are high resistance to these agents are mostly related to mutations in the drug targets, topoisomerase IV and DNA gyrase [11]. However, other than these enzyme mutations, fluoroquinolone resistance can also be mediated by drug efflux, a mechanism that is not well characterized. Bacterial multidrug resistance may be mediated by the overexpression of efflux pump [12]. This overexpression of efflux pump is mostly related to the mutations within the promoter region of the MDR efflux pump gene.

Efflux pumps are membrane protein that are present in cytoplasmic membrane in bacteria cell. The function of efflux pumps is for expelling and extruding harmful substances out from the bacterial cell [13]. Efflux pumps have their own substrate specificity, where the substrate is specific to the antibiotic or a class of antibiotic. For MDR efflux pumps, they are capable of extrude more than one class of antibiotic and other structural antimicrobial compounds [11]. They are major facilitator superfamily (MFS), the small multidrug resistance family (SMR), the resistance-nodulation cell division (RND) superfamily, the multidrug and toxic compound extrusion (MATE) family, and the adenosinetriphosphate (ATP) binding cassette (ABC) superfamily) [13]. Most fluoroquinolone drugs are small enough to cross the cytoplasmic membrane and then reach their targets in the cell cytoplasm. They also have charge characteristics that allow them to cross the outer membrane through porin proteins, which form general diffusion channels and can cross the cytoplasmic membrane via diffusion [14]. Recently, resistance caused by reduced accumulation has been shown to require the presence and enhanced expression of endogenous efflux systems that actively pump drug from the cytoplasm in S. aureus [15]. There are several MDR efflux pumps related to fluroquinolones resistance that have been identified in the $S$. aureus such as NorA, NorB, MepA and MdeA [15]. Therefore, the objectives of this study were to identify the ciprofloxacin MDR efflux pumps presence in our MDR S. aureus and to assess the activity of the efflux pumps. Detection of MDR efflux pump in our MDR S. aureus isolates is crucial for explaining the fluroquinolones resistance characteristic displayed by these isolates. Absence of known efflux pump ARGs in these isolates might be a good model in providing us fundamental knowledge to solve the antibiotic resistance problem.

\section{Method}

\subsection{Isolation of MDR S. aureus from hospital wastewater}

Hospital wastewater was taken from local hospital wastewater and were directly processed after sampling. For the isolation of MDR S. aureus, a selective medium, Mannitol Salt agar (MSA) was used. A serial dilution of the wastewater was performed and each of the dilution was spread on the MSA plate and incubated at $37{ }^{\circ} \mathrm{C}$ for 24 hours. A pure culture of 9 S. aureus isolates obtained were recognized by the appearance of yellow colonies on MSA.

\subsection{Phenotypic test of MDR S. aureus isolates}

These 9 S. aureus isolates were grown on the MSA containing therapeutic concentration of ampicillin $(30 \mu \mathrm{L} / \mathrm{L})$, gentamicin (10), trimethoprim-sulfamethoxazole (1.25/23.75), erythromycin (15), chloramphenicol (30), tetracycline (15), kanamycin (30), nalidixic acid (30), vancomycin (15) and ciprofloxacin (5) to observe for the multidrug resistance 
characteristic. These 9 isolates were also subjected to Kirby Bauer disk diffusion test for the zone of inhibition diameter. These was done according to the CLSI guidelines.

\subsection{Bacterial DNA extraction}

Total DNA was isolated from $S$. aureus grown in $30 \mathrm{ml}$ of nutrient broth at $37{ }^{\circ} \mathrm{C}$ with shaking overnight. Cells were harvested by centrifugation at $10,000 \mathrm{rpm}$ for 2 minutes. The cell pellet was resuspended in $480 \mu \mathrm{L}$ of EDTA and $120 \mu \mathrm{L}$ of $20 \mathrm{mM}$ lysozyme. The solution was incubated for 1 hour at $37{ }^{\circ} \mathrm{C}$ and then centrifuged at $10,000 \mathrm{rpm}$ for 2 minutes. DNA was extracted with phenol/chloroform and precipitated in $70 \%$ ethanol for purification. The precipitated DNA was dissolved in $70 \mu \mathrm{L}$ of sterile ultrapure water and stored at $-20{ }^{\circ} \mathrm{C}$ until used.

\subsection{PCR for Ciprofloxacin Efflux Pump Genes}

PCR amplification was performed using a $20 \mu \mathrm{l}$ reaction mixture composed of $12.3 \mu \mathrm{L}$ sterilized Milli-Q water, $4.0 \mu \mathrm{L} 5 \mathrm{x}$ PCR buffer, $1.6 \mu \mathrm{L} \mathrm{MgCl}_{2}, 0.4 \mu \mathrm{L} \mathrm{dNTPs}, 0.3 \mu \mathrm{L}$ of each forward and reverse primers, $0.1 \mu \mathrm{L}$ Taq polymerase, and $2 \mu \mathrm{L}$ of purified DNA. The PCR protocol consisted of denaturation for 5 min at $94^{\circ} \mathrm{C} ; 35$ cycles of 30 sec at $98{ }^{\circ} \mathrm{C}$, $45 \mathrm{sec}$ at $55^{\circ} \mathrm{C}$, and $45 \mathrm{sec}$ at $72{ }^{\circ} \mathrm{C}$; and a final extension step of $10 \mathrm{~min}$ at $72{ }^{\circ} \mathrm{C}$. Amplified PCR products were electrophoresed on a $2 \%$ agarose gel in a $1 \mathrm{X}$ Tris-acetate EDTA (TAE) buffer, stained with Diamond Nucleic Acid Dye (Promega, Madison, WI), and viewed under UV light. Nucleotide sequences and annealing temperatures for each primer used in this study are shown in Table 1.

Table 1 - PCR primers with MDR efflux pumps gene targeted used in this study.

\begin{tabular}{|c|c|c|c|c|}
\hline $\begin{array}{c}\text { Genes } \\
\text { targeted }\end{array}$ & Primer sequence (5'-3') & $\begin{array}{c}\text { Amplicon } \\
\text { size (bp) }\end{array}$ & Ta $\left({ }^{\circ} \mathrm{C}\right)$ & Reference \\
\hline norA & $\begin{array}{l}\text { F; TTCACCAAGCCATCAAAAAG } \\
\text { R; CTTGCCTTTCTCCAGCAATA }\end{array}$ & 620 & 45 & [11] \\
\hline mdeA & $\begin{array}{l}\text { F; AACGCGATACCAACCATTC } \\
\text { R; TTAGCACCAGCTATTGGACCT }\end{array}$ & 677 & 53 & [11] \\
\hline терА & $\begin{array}{l}\text { F; ATGTTGCTGCTGCTCTGTTC } \\
\text { R; TCAACTGTCAAACGATCACG }\end{array}$ & 718 & 53 & [11] \\
\hline
\end{tabular}

F: Forward primer R: Reverse primer

\subsection{Ethidium Bromide Agar Cartwheel Method (EtBrCW)}

Tryptic soy agar (TSA) plates containing different concentrations $(0.5,1.0 .1 .5,2.0$, and $2.5 \mathrm{mg} / \mathrm{mL})$ of ethidium bromide (EtBr) were used to assess the activity of efflux pumps. S. aureus isolates were swabbed onto EtBr-TSA plates as shown in Fig. 1 below and incubated at $37^{\circ} \mathrm{C}$ for 16 hours. For a control, a TSA plate with $0 \mathrm{mg} / \mathrm{mL}$ of EtBr was prepared. After incubation, all agar plates were viewed and examined under a Gel-Doc XR apparatus (BioRad, Hercules, CA) and the TSA plates were photographed.
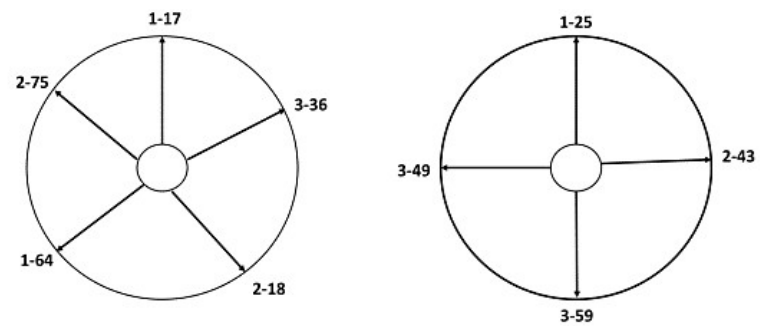

Fig. 1 - 9 MDR S. aureus isolates were swabbed onto EtBr agar plate of TSA according to these patterns

\section{Results}

\subsection{Susceptibility data of the 9 isolates}

All the 9 isolates were able to grow well on MSA containing certain concentration of antibiotics and were resistant to all the antibiotic tested (Table 2). MDR bacteria is defined when the bacteria are resistance to more than 3 antibiotic classes tested. 
Table 2 - Antibiotic susceptibility in the MDR S. aureus isolates

\begin{tabular}{|c|c|c|c|c|c|c|c|c|c|c|}
\hline \multirow[t]{2}{*}{ ISOLATES } & \multicolumn{10}{|c|}{ ANTIBIOTICS } \\
\hline & $\begin{array}{l}\mathbf{A} \\
\mathbf{M} \\
\end{array}$ & CFX & $\begin{array}{l}\mathbf{G M} \\
\mathbf{N} \\
\end{array}$ & $\begin{array}{l}\text { KN } \\
\text { M } \\
\end{array}$ & $\begin{array}{l}\text { ER } \\
\text { M }\end{array}$ & $\begin{array}{l}\mathbf{T} \\
\mathbf{M}-\end{array}$ & $\begin{array}{l}\text { NA } \\
\mathbf{L}\end{array}$ & $\begin{array}{l}\mathbf{C M} \\
\mathbf{P}\end{array}$ & $\begin{array}{l}\mathbf{T E} \\
\mathbf{T}\end{array}$ & $\begin{array}{l}\text { VA } \\
\mathbf{N}\end{array}$ \\
\hline $1-$ & $\mathrm{R}$ & $\mathrm{R}$ & I & $\mathrm{R}$ & $\mathrm{R}$ & $\mathrm{R}$ & $\mathrm{R}$ & $\mathrm{R}$ & $\mathrm{R}$ & $\mathrm{R}$ \\
\hline $1-$ & $\mathrm{R}$ & $\mathrm{R}$ & $\mathrm{R}$ & $\mathrm{R}$ & $\mathrm{R}$ & $\mathrm{R}$ & $\mathrm{R}$ & $\mathrm{R}$ & $\mathrm{R}$ & $\mathrm{R}$ \\
\hline $1-$ & $\mathrm{R}$ & $\mathrm{R}$ & $\mathrm{R}$ & $\mathrm{R}$ & $\mathrm{R}$ & $\mathrm{R}$ & $\mathrm{R}$ & I & I & $\mathrm{R}$ \\
\hline $2-$ & $\mathrm{R}$ & $\mathrm{R}$ & $\mathrm{R}$ & $\mathrm{R}$ & $\mathrm{R}$ & $\mathrm{R}$ & $\mathrm{R}$ & $\mathrm{R}$ & I & $\mathrm{R}$ \\
\hline $2-$ & $\mathrm{R}$ & $\mathrm{R}$ & $\mathrm{R}$ & $\mathrm{R}$ & $\mathrm{R}$ & $\mathrm{R}$ & $\mathrm{R}$ & $\mathrm{R}$ & $\mathrm{R}$ & $\mathrm{R}$ \\
\hline $2-$ & $\mathrm{R}$ & $\mathrm{R}$ & $\mathrm{R}$ & $\mathrm{R}$ & $\mathrm{R}$ & $\mathrm{R}$ & $\mathrm{R}$ & $\mathrm{R}$ & $\mathrm{R}$ & $\mathrm{R}$ \\
\hline $3-$ & $\mathrm{R}$ & $\mathrm{R}$ & $\mathrm{R}$ & $\mathrm{R}$ & $\mathrm{R}$ & $\mathrm{R}$ & $\mathrm{R}$ & $\mathrm{R}$ & I & $\mathrm{R}$ \\
\hline $3-$ & $\mathrm{R}$ & $\mathrm{R}$ & $\mathrm{R}$ & $\mathrm{R}$ & $\mathrm{R}$ & $\mathrm{R}$ & $\mathrm{R}$ & $\mathrm{R}$ & $\mathrm{R}$ & $\mathrm{R}$ \\
\hline $3-$ & $\mathrm{R}$ & $\mathrm{R}$ & $\mathrm{R}$ & $\mathrm{R}$ & $\mathrm{R}$ & $\mathrm{R}$ & $\mathrm{R}$ & $\mathrm{R}$ & $\mathrm{R}$ & $\mathrm{R}$ \\
\hline
\end{tabular}

\subsection{Molecular detection of efflux pump genes}

Our results show that a high percentage of our isolates did not possess fluroquinolones MDR efflux pump genes. Amplification of the selected genes by PCR showed only 2 isolates possessed MDR efflux pump. A single clear band was observed on the agarose gel for isolate 3-36 at $677 \mathrm{bp}$ and 3-59 at $718 \mathrm{bp}$, indicating the presence of mepA and mdeA genes in these isolates (Fig.2). However, none of the isolates showed presence of norA gene (Table 3).

Table 3 - Detection of known efflux pump ARGs in the MDR S. aureus isolates

\begin{tabular}{|c|c|c|c|c|c|c|c|c|c|}
\hline \multirow[t]{2}{*}{ GENES } & \multicolumn{9}{|c|}{ ISOLATE } \\
\hline & $1-17$ & $1-25$ & $1-64$ & $2-$ & $\mathbf{S}$ & $2-75$ & $3-36$ & $3-49$ & $3-59$ \\
\hline parC & - & - & + & - & - & - & + & + & - \\
\hline gyrA & + & - & - & + & + & - & + & - & - \\
\hline norA & - & - & - & - & - & - & - & - & - \\
\hline mdeA & - & - & - & - & - & - & - & - & + \\
\hline mepA & - & - & - & - & - & - & + & - & - \\
\hline
\end{tabular}

(a)

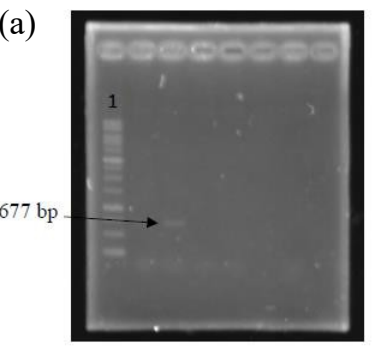

(b)

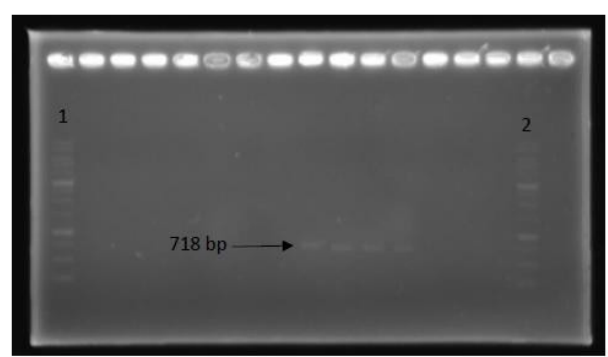

Fig. 2 - a) PCR amplification for mdeA appeared as a single band with a size fragment equals to 677 bp in 3-59 isolate b) PCR amplification for mepA appeared as a single band with a size fragment equals to 718 bp in 3-36 isolate

\subsection{Efflux Pump Activity by EtBrCW}

EtBrCW result exhibited similar fluorescence for each $S$. aureus isolates on agar plates containing increasing concentrations of $\mathrm{EtBr}$ (data not shown) when compare to the control. Even at high concentration of EtBr $(2.5 \mathrm{mg} / \mathrm{L})$, the fluorescence of all isolates remains the same and this indicates the efflux pump present in these isolates have very low efflux activity system because they do not capable to extrude the EtBr from the cell.

\section{Discussion}

Our result showed that all $9 \mathrm{~S}$. aureus isolates were resistant to 10 antibiotics tested indicated that the antibiotic resistance problem in Malaysia is increasing. These bacteria were isolated from local hospital wastewater, which contain high concentration of antibiotics and pathogenic bacteria. Continuous release of antibiotic into the wastewater 
has provided antibiotic selective pressure that triggered the bacteria to acquire the resistance genetic materials from other bacteria species [16]. In addition, the climate in Malaysia could be one of the key factors influencing the transmission of the ARGs among the bacteria. It has been mentioned by Leekha et al. (2012) that the climate may play a role in contributing to antibiotic resistance in S. aureus [17]. Hot and high humidity condition in the country speed up the bacterial replication rate and transmission. Mutations in chromosomal DNA occur at a low level every time the DNA is copied during growth. This variation causes differences in how the organism interacts with the environment, which leads to evolution by natural selection when the population (each containing different mutants) is faced with a selective pressure [18]. Antibiotics are a strong selective pressure for bacterial populations. They remove bacteria that do not have the relevant resistance-causing chromosomal mutations, and select for bacteria that have the mutations [18]. Pathogen with new genetic material are evolving to adapt to the condition (bacterial has the tendency to acquire the new genetic material which allows them to survive in certain conditions) and leading to the spread of new pathogen with new genetic characteristics.

These MDR bacteria were furthered subjected to PCR analysis to observe for the known ARGs responsible for their resistance. Interestingly, PCR amplification showed that high percentage of MDR S. aureus isolates did not have MDR efflux pump genes. In our previous paper, PCR amplification has been done on the same isolates for detection of gyrA and parC genes. 6 isolates (1-17, 1-64, 2-18, 2-43, 3-36 and 3-49) possessed these 2 genes [19]. But the rest of the MDR isolates (1-25, 2-75 and 3-59) showed absence of parC and gyrA genes. These showed that there may be other resistance mechanism responsible for the resistance. Therefore, in this study, we have selected the isolates that showed resistance to fluroquinolone to observe if other mechanism of resistance (expelling the drugs out through efflux pump), existed in our MDR isolates. However, PCR result of these MDR isolates demonstrated that only 2 efflux pump genes were amplified (mepA and $m d e A)$.

The selection of the MDR efflux pump genes used in this study are selected based on their frequent occurrence in phenotypically resistant $S$. aureus isolates especially NorA efflux pump. NorA efflux pump is one of the most common efflux pumps studied in S. aureus [13]. NorA efflux transporter was first identified in 1990 and responsible for intermediate level of resistance to fluroquinolones in S. aureus [13]. Several studies have shown that NorA can extrude an array of chemically and structurally dissimilar compounds such as hydrophilic fluroquinolones, EtBr and quaternary compounds [20,21]. Increased resistance to fluroquinolone biocides and dyes has been associated with Nor-A mediated efflux, via the increased expression of the norA gene [22]. Recent study showed that frequency of NorA overexpressing strains is high in S. aureus isolates collected from various regions in the United State [23]. In addition to that, a study in Portugal also showed that all $S$. aureus isolates carried norA gene [12]. However, in this study, all 9 MDR isolates showed absence of norA gene, which is contradicted to what the other studies have found. This indicate that norA gene is not involved contributing to the MDR resistance phenotypes in our 9 isolates.

Other than NorA efflux pump, another important fluroquinolone MDR efflux pump is MepA. MepA is encoded by chromosomal gene mepA and it was the first MDR transporter from MATE family in S. aureus [13]. MepA was found to be associated with MDR phenotype and conferring low level of resistance to quaternary ammonium compounds, $\mathrm{EtBr}$, as well as antibiotic from class of the glycylcyclines [13]. However, it was shown that fluroquinolone such as ciprofloxacin is a weak substrate of MepA [24,25]. Detection of mepA gene in the 3-36 isolate indicates that expression of терA gene may contribute slightly to the fluroquinolone resistance phenotype shown by this isolate together with high expression of parC and gyrA genes. Although high level of resistance may not occur as a result of MDR efflux pump alone, the association of over-expression of specific genes among highly resistant clinical isolates cannot be ignored [26,27]. Therefore, intrinsic resistance to antibiotics of some isolates may be largely due to efflux systems $[28,29]$. Synergic reaction increases in resistance has been seen with over expression of efflux systems as well as target site mutations can lead to highly resistant bacteria that are difficult to treat with the antibiotics that are currently available [13].

Efflux pump MdeA, was encoded by the chromosomal gene mdeA and it was identified in an open reading frame expression library of the $S$. aureus genome [30]. The overexpression of $m d e A$ was associated to increased resistance to the biocides benzalkonium chloride, $\mathrm{EtBr}$ and to the antibiotics novobiocin, mupirocin and fusidic acid [30]. A study has shown that fluroquinolones ciprofloxacin is a weak substrate of this pump [30]. In this study, we detected the presence of mdeA gene in our 3-59 isolate. In contrast to other study, they identified that all S. aureus isolates carried the mdeA gene [13]. Our result indicates that, despite being a weak substrate to the MdeA pump, the expression of this gene may have contributed to the MDR resistance phenotype. According to Huang et al., (2004), overexpression of this gene can be achieved by the occurrence of mutations in the mdeA promoter region [31].

EtBrCW is a widely used agar-based method that has been modified to rapidly screen for MDR isolates that show an over expression of their efflux systems [32]. This system relies on the ability of the bacteria to expel a fluorescent molecule that is substrate for most efflux pumps, $\mathrm{EtBr}$ [32]. This method has been proved to be a valuable tool for rapid screening of efflux pump activity [13]. Analysis of the efflux pump activity by EtBrCW in our isolates showed these isolates have low efflux pump activity. Even at high concentration of EtBr, the isolates showed similar fluorescence. According to Martins et al., (2010), if isolates shows fluorescence at lower EtBr concentration, these isolates are 
identified to have less active efflux systems compared to that which fluorescence at high EtBr concentrations [32]. This result is consistent with the PCR result which also showed absence of most known efflux pump genes except for isolate 3-36 and 3-59. Low efflux pump activity indicates that these bacteria may not be using efflux pump as their primary way of resisting the antibiotic action, but also other resistance mechanism which need further exploration. Their resistance in the $S$. aureus isolates could be mediated by other different mechanism of resistant excluding mutations of enzymes. However, in this study, we do not assess the expression of the efflux pump genes through determination of MIC values for ciprofloxacin, and it is a limitation that need to be noted.

\section{Conclusion}

From this study, it can be concluded that MDR $S$. aureus were resistant due to the presence of genes encoded for enzymes mutations and efflux pumps. However, 2 of the MDR isolates (1-25 and 2-75) showed absence of these genes, indicating some new mechanism of resistance must be existed and further experiments on these 2 unique isolates need to be carry out. A new resistance mechanism could be associated with the environmental conditions in Malaysia.

\section{Acknowledgement}

The authors would like to express their gratitude to Malaysia-Japan International Institute of Technology (MJIIT) for financial support.

\section{References}

[1] Goldstein, R.E.R., Micallef, S.A, Gibbs, S.G., Davies, J., \& Sapkota, A. (2012). Methicillin-resistant staphylococcus aureus (MRSA) detected at Four U.S. Wastewater Treatment Plants. Environmental Health Perspectives. 120,1551-1558.

[2] Ahn, Y., \& Choi, J. (2016). Bacterial communities and antibiotic resistance communities in a full-scale wastewater treatment plant by high throughput pyrosequencing. Water. 8,580-586.

[3] Harris, S.J., Cormican, M., \& Cummins, E. (2012). Antimicrobial residues and antimicrobial resistant bacteria: impact on the microbial environment and risk to human health- a review. Human and Ecological Risk Assessment International Journal. 18,767-809.

[4] Jackson, R.W., Vinatzer, B., Arnold, D.L., Dorus, S., \& Murillo, J. (2011). The influence of the accessory genome on bacterial pathogen evolution. Mobile Genetics Element. 1,55-65.

[5] Ragan, M.A., \& Beiko, R.G. (2009). Lateral genetic transfer: open issues. Philosophy Transactions of the Royal Society B. Biological Science. 364,2241-2251.

[6] Miskiah, F.G., Nuraiffa, S.A., Husnul, A.T., Remy, R.M.A.Z., Fazliani, S., \& Zawawi, D. (2018). Isolation and identification of pathogenic bacteria at riverbank filtration study site: Lubuk Buntar, Kedah, Malaysia. International Journal of Integrated Engineering. 10,146-151.

[7] Norshuhaila, M.S., Masayu, M., \& Saidatu, S.K. (2015). Fate of pathogen indicators during extended aeration of wastewater treatment. International Journal of Integrated Engineering. 7,1-5.

[8] Harkins., P.C., Pichon., B., Doumith., M., Parkhill., J \& Holden., T.G. (2017). Methicillin resistant staphylococcus aureus emerged long before the introduction of methicillin into clinical practice. Genome Biology. $18,130-137$.

[9] Poole, K. (2000). Minireview: Efflux-Mediated Resistance to Fluoroquinolones in Gram-Positive Bacteria and the Mycobacteria, 44,2595-2599.

[10] G.Y. Lesher. (1962). 1,8- Naphthyridine derivatives. A new class of chemotherapeutic agents. Journal of Medicinal Chemistry, 5,1063-1065.

[11] Hooper., D.C. (2002). Fluoroquinolone resistance among Gram-positive cocci. Lancet Infectious Diseases, 2 , 530-538.

[12] Costa, S. S., Falcão, C., Viveiros, M., Machado, D., Martins, M., Melo-cristino, J., \& Couto, I. (2011). Exploring the contribution of efflux on the resistance to fluoroquinolones in clinical isolates of staphylococcus aureus. BMC Microbiology. 11,241-246.

[13] Costa, S.S. (2013). Multidrug efflux pumps in staphylococcus aureus: An update. The Open Microbiology Journal. 7,59-71.

[14] Hooper, D. C. (2001). Emerging mechanisms of fluoroquinolone resistance, Emerging Infectious Diseases Journal. 7,337-341.

[15] Martins, M., Couto, I., Viveiros, M., \& Amaral, L. (2006). An instrument-free method for the demonstration of efflux pump activity of bacteria. In Vivo. 20,657-64.

[16] Iversen, A., Kühn, I., Franklin, A. \& Möllby, R. (2002). High prevalence of vancomycin-resistant enterococci in Swedish sewage. Appled Environmental Microbiology. 68,2838-2842. 
[17] Leekha, S., Diekema, D. J. \& Perencevich, E. N. (2012). Seasonality of staphylococcal infections. Clinical Microbiology and Infections. 18,927-933.

[18] Bengtsson-palme, J., Kristiansson, E., \& Larsson, D.G.J. (2018). Environmental factors influencing the development and spread of antibiotic resistance. FEMS Microbiology Reviews. 42,68-80.

[19] Norayuni, S., Yusaimi, Y. A., Sugiura, N., Iwamoto, K., Goto, M., \& Hara, H. (2016). Phenotypic and genetic characterization of multidrug-resistant staphylococcus aureus in the tropics of southeast Asia. Microbiology. 162,2064-2074.

[20] Yoshida, H., Bogaki, M., Nakamura, S., Ubukata, K., \& Konno, M. (1990). Nucleotide sequence and characterization of the staphylococcus aureus norA gene, which confers resistance to quinolones. Journal of Bacteriology. 172,6942-6949.

[21] Neyfakh, A.A., Borsch, C.M., \& Kaatz, G.W. (1993). Fluroquinolone resistance protein NorA of staphylococcus aureus is a multidrug efflux transporter. Antimicrobial Agents and Chemotherapy. 37,128-129.

[22] Kaatz, G., Seo, S. \& Ruble, C. (1993). Efflux mediated fluroquinolone resistance in Staphylococcus aureus. Antimicrobial Agents and Chemotherapy. 37,1086-1094.

[23] Kosmidis, C., Schindler, B., Jacinto, P., Patel, D., Bains, K., Seo, S. \& Kaatz, G. (2012). Expression of multidrug resistant efflux pump genes in clinical and environmental isolates of staphylococcus aureus. International Journal of Antimicrobial Agents. 40,204-209.

[24] Kaatz, G.W., McAleese, F., Seo, S.M. (2005). Multidrug resistance in staphylococcus aureus due to overexpression of a novel multidrug and toxin extrusion (MATE) transport protein. Antimicrobial Agents and Chemotheraphy. 49,1857-64.

[25] Mcaleese, F., Petersen, P., Ruzin, A., Dunman, P. M., Murphy, E., Projan, S. J., \& Bradford, P. A. (2005). A novel MATE family efflux pump contributes to the reduced susceptibility of laboratory-derived staphylococcus aureus mutants to tigecycline, 49,1865-1871.

[26] Piddock, L.J.V. (2006). Clinically relevant chromosomally encoded multidrug resistance efflux pumps in bacteria, 19,382-402.

[27] Regan, E. O., Quinn, T., Page, J., Mccusker, M., \& Piddock, L. (2009). Multiple regulatory pathways associated with high-level ciprofloxacin and multidrug resistance in salmonella enterica serovar enteritidis: involvement of ramA and other global regulators. Antimicrobial Agents and Chemotherapy. 53,1080-1087.

[28] Mccusker, M. P., Pagès, J., \& Amaral, L. (2013). A simple method for assessment of MDR bacteria for overexpressed efflux pumps. The Open Microbiology Journal. 7,72-82.

[29] Okusu, H., \& Ma, D. (1996). AcrAB efflux pump plays a major role in the antibiotic resistance phenotype of escherichia coli multiple- antibiotic-resistance (Mar) mutants. Journal of Bacteriology. 178,306-308.

[30] Huang, J., O’Toole, P. W., Shen, W., Amrine-Madsen, H., Jiang, X., Lobo, N., \& McDevitt, D. (2004). Novel chromosomally encoded multidrug efflux transporter MdeA in staphylococcus aureus. Antimicrobial Agents and Chemotherapy, 48,909-917.

[31] Yamada, Y., Hiota, S. S., Izushima, T. M., Uroda, T. K., \& Suchiya, T. T. (2006). Functional gene cloning and characterization of MdeA, a multidrug efflux pump from staphylococcus aureus. Biological and Pharmaceutical Bulletin. 29,801-804.

[32] Martins, M., Viveiros, M., Couto, I., Costa, S. S., Pacheco, T., Fanning, S., \& Amaral, L. (2011). Identification of efflux pump-mediated multidrug-resistant bacteria by the ethidium bromide-agar cartwheel method. In Vivo. $25,171-178$. 